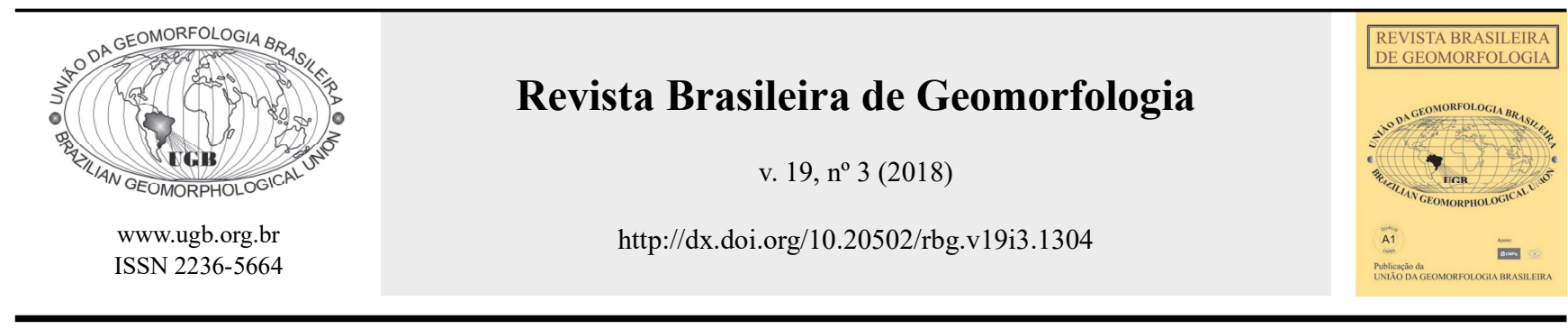

\title{
EVOLUÇÃO DA REDE DE DRENAGEM E EVIDÊNCIAS DE ANTIGAS CONEXÕES ENTRE AS BACIAS DOS RIOS GRANDE E SÃO FRANCISCO NO SUDESTE BRASILEIRO
}

\section{DRAINAGE EVOLUTION AND EVIDENCE OF ANCIENT CONNECTIONS BETWEEN THE GRANDE AND SÃO FRANCISCO RIVER BASINS IN SOUTHEASTERN BRAZIL}

\author{
Éric Andrade Rezende \\ Departamento de Geologia, Universidade Federal de Ouro Preto \\ Campus Morro do Cruzeiro, Ouro Preto, Minas Gerais. CEP 35400-000. Brasil
}

E-mail:ear.88@hotmail.com

André Augusto Rodrigues Salgado

Departamento de Geografia, Universidade Federal de Minas Gerais Avenida Antônio Carlos, 6627, Belo Horizonte, Minas Gerais. CEP 31270-901. Brasil E-mail: aarsalgadoufmg@gmail.com

Paulo de Tarso Amorim Castro

Departamento de Geologia, Universidade Federal de Ouro Preto Campus Morro do Cruzeiro, Ouro Preto, Minas Gerais. CEP 35400-000. Brasil

E-mail: ptacastro@gmail.com

\section{Informações sobre o Artigo}

Data de Recebimento: 10/09/2017

Data de Aprovação: $15 / 05 / 2018$

Palavras-chave:

Captura Fluvial; Incisão

Fluvial; Superimposição.

\section{Keywords:}

River Capture; Fluvial Incision; Superimposition.

\section{Resumo:}

O presente trabalho investigou a evolução da rede de drenagem na alta/média bacia do Rio Grande, com foco em evidências de antigas conexões entre esta bacia e a bacia do Rio São Francisco no sudeste brasileiro. Foi executada a análise conjunta de registros sedimentares, anomalias de drenagem, eixos de soerguimento e dados termocronológicos disponíveis. Feições como um baixo divisor anômalo, um cotovelo de drenagem, uma garganta e um antigo eixo de soerguimento evidenciam que o alto curso do Rio Grande, hoje pertencente à bacia hidrográfica do Rio Paraná, encontrava-se previamente direcionado para norte, rumo ao Cráton do São Francisco. O divisor ancestral entre as duas bacias hidrográficas coincidia com o eixo soerguido de direção geral NNW-SSE ao longo das intrusões alcalinas Neocretáceas que bordejam a nordeste a Unidade geotectônica Bacia do Paraná. O rompimento do divisor ancestral e a consequente captura fluvial provavelmente ocorreram após um soerguimento generalizado no Mioceno Médio, que causou a superimposição da drenagem a partir de uma paleosuperfície mais regular e a abertura de depressões. O baixo divisor anômalo na região de Pimenta-MG corresponde a um expressivo registro morfológico do paleovale que conectava as duas bacias atualmente separadas. Taxas médias de incisão de longo-termo foram estimadas em cerca de $10 \mathrm{~m} / \mathrm{Ma}$, com base no posicionamento das formações Marília e Itaqueri adjacentes ao médio vale do Rio Grande. 


\begin{abstract}
:
This study investigated the drainage network evolution in the upper/middle Grande River basin, focusing on evidence of ancient connections between this basin and the São Francisco River basin in southeastern Brazil. A combined analysis of sedimentary records, drainage anomalies, uplift axes and available thermochronological data was performed. Features such as an anomalous low divide, a river elbow, a gorge and an ancient uplift axis evidence that the high course of the Rio Grande, currently belonging to the Paraná River basin, was previously directed to the São Francisco Craton (northward). The ancestral divide between the cited hydrographic basins coincided with the uplifted axis of general direction NNW-SSE along the Neocretaceous alkaline intrusions bordering the Paraná Basin. The rupture of the ancestral divide and the consequent river capture probably occurred after generalized uplift in the Middle Miocene, which caused the drainage superimposition on a more regular paleosurface and the excavation of depressions. The anomalous low divide in the region of Pimenta-MG corresponds to an expressive morphological record of paleovale that connected the two basins currently separated. Average long-term incision rates were estimated at about $10 \mathrm{~m} / \mathrm{Ma}$, based on the positioning of the Marília and Itaqueri formations adjacent to the middle Grande River valley.
\end{abstract}

\section{Introdução}

Um importante processo envolvido na evolução dos sistemas fluviais é o rearranjo de drenagem. De acordo com Bishop (1995), esse processo corresponde à transferência parcial ou total do fluxo de um rio para outro, podendo ocorrer em diferentes escalas espaciais. Rearranjos podem estar relacionados a mudanças no nível de base e permitem a fusão de sistemas fluviais previamente desconectados ou a divisão/desvio de um sistema já existente (GALLAGHER, 2012). A captura fluvial é o mais notável tipo de rearranjo e se caracteriza pela transferência de área entre bacias, porém, com a preservação das linhas de drenagem (BISHOP, 1995). Capturas são processos geológicos importantes que podem alterar drasticamente a proveniência e a mineralogia de sedimentos aluviais, além de provocar mudanças nos padrões de migração de espécies aquáticas e nas taxas de erosão de determinadas áreas (BISHOP, 1995; PEDERSON, 2001; WILLETT et al., 2014). Uma clara alteração nas distribuições bióticas e/ou na composição de sedimentos acumulados em bacias sedimentares, deltas e terraços podem indicar a ocorrência de uma captura a montante (PEDERSON, 2001).

O reconhecimento de que uma captura fluvial ocorreu no passado é comumente baseado em observações como cotovelos de captura, vales secos, canais decapitados e afluentes farpados (barbed tributaries) (PEDERSON, 2001). De acordo com Twidale (2007), todas as capturas resultam em incomuns mudanças no alinhamento de canais, como exemplificado em inversões de direção de drenagem.
Bishop (1995) salienta ainda que em estudos desta natureza a dimensão vertical da denudação não pode ser negligenciada, pois promove incertezas na reconstrução de linhas de drenagem em níveis crustais prévios.

Entre os exemplos mais notáveis de capturas fluviais conhecidos no sudeste brasileiro destaca-se a subtração das antigas cabeceiras do Rio Tietê pelo médio Rio Paraíba do Sul na região do "Cotovelo de Guararema” (KING, 1956; AB'SABER, 1957; RICCOMINI et al., 2010). King (1956) refere-se a esse rompimento da antiga conexão entre o alto Paraíba do Sul e o alto Tietê como um dos mais espetaculares casos de captura conhecidos no mundo. Na bacia do Rio Grande, um dos formadores do Rio Paraná, há evidências morfológicas de uma captura ainda mais expressiva, na qual houve a transferência de área de drenagem muito superior àquela envolvida na famosa captura promovida pelo Rio Paraíba do Sul.

Neste contexto, o presente trabalho investigou a evolução da rede de drenagem na alta/média bacia do Rio Grande (Figura 1), com base em evidências de um importante rearranjo de drenagem que rompeu uma antiga ligação entre esta bacia e a bacia do Rio São Francisco. Para isso foi adotada a estratégia proposta por Bishop (1995) e Conti (2012) que leva em conta tanto a resposta das formas de relevo aos processos de drenagem quanto os registros sedimentares aluviais. Deste modo, foi executada a análise conjunta de registros sedimentares (rochas e sedimentos inconsolidados), anomalias de drenagem, eixos de soerguimento associados a províncias alcalinas Neocretáceas e histórias térmicas modeladas a partir de dados termocronológicos previamente publicados. 


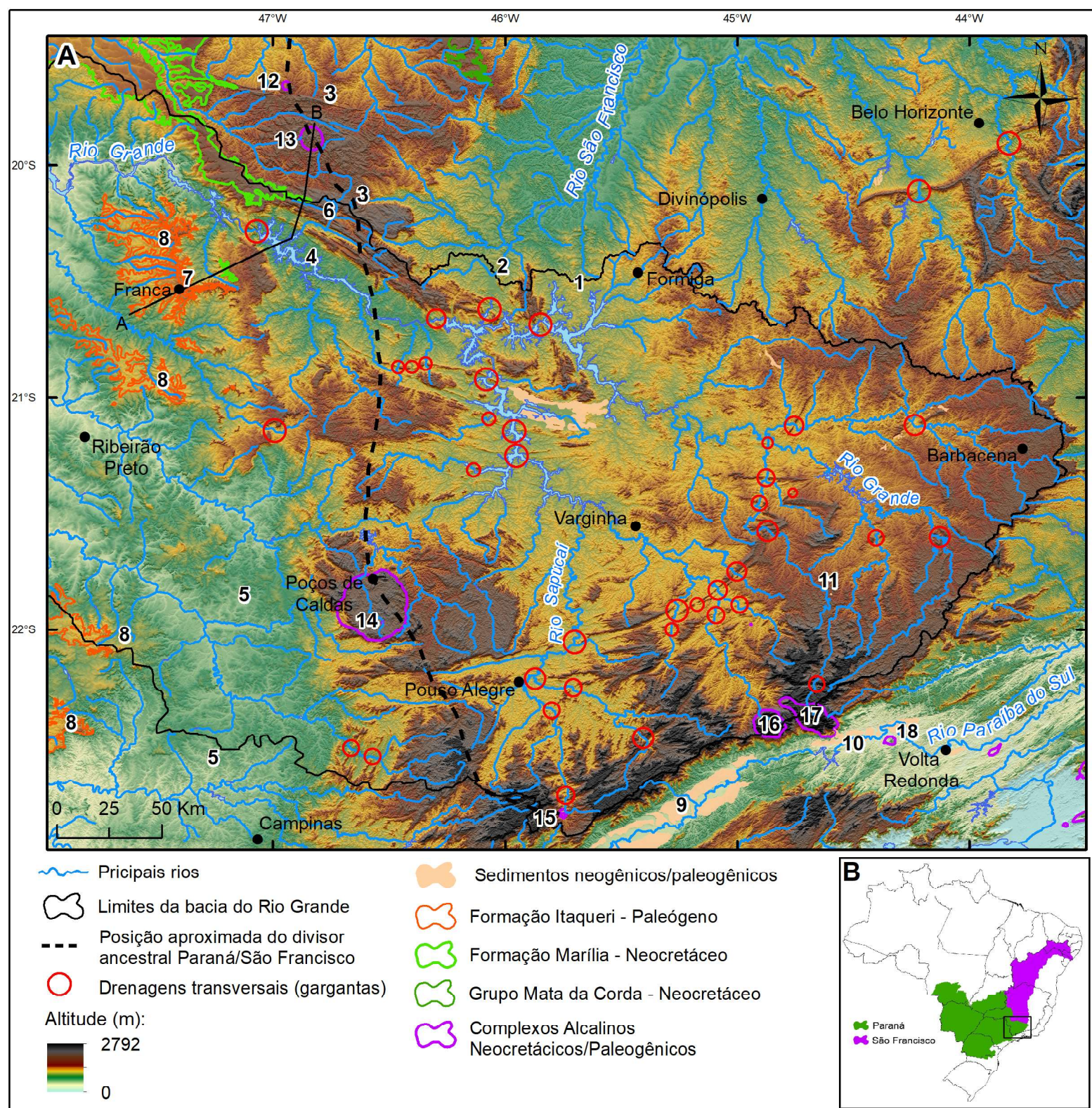

1: Baixo divisor de Pimenta; 2: Baixo divisor de Piumhi; 3: Soerguimento Alto Paraníba; 4: Depressão periférica do Rio Grande; 5: Depressão periférica paulista; 6: Serra da Canastra; 7: Planalto de Franca; 8: Cuestas; 9: Bacia de Taubaté; 10: Bacia de Resende; 11: Bacia de Aiuruoca

Complexos Alcalinos: 12: Barreiro; 13: Tapira; 14: Poços de Caldas; 15: Ponte Nova; 16: Passa Quatro; 17: Itatiaia; 18: Morro Redondo

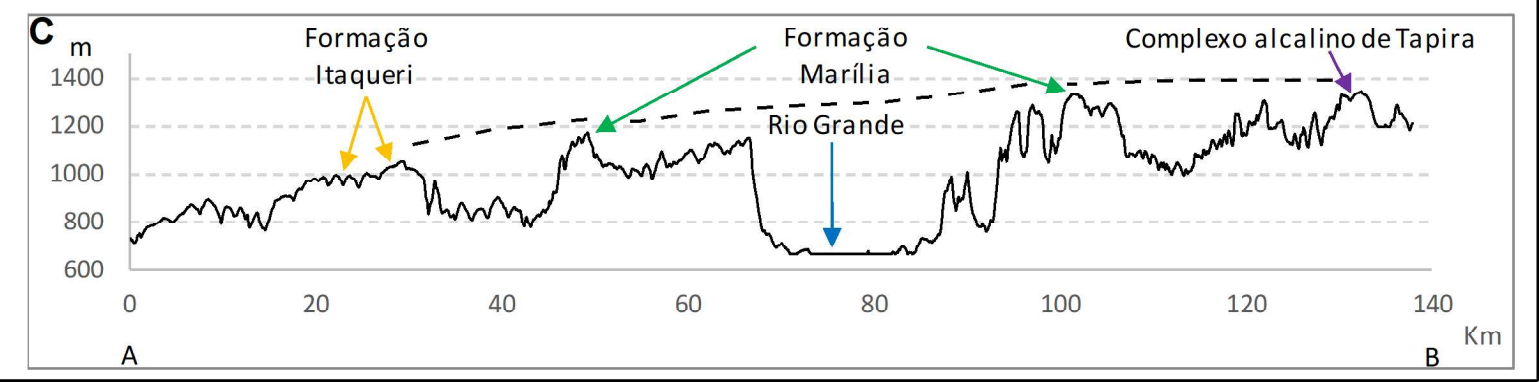

Figura 1 - A) Modelo Digital de elevação da alta média bacia do Rio Grande e adjacências contendo as principais feições e unidades sedimentares suprabasálticas. B) Localização das bacias dos rios Paraná e São Francisco e da área de estudo no Brasil. C) Perfil topográfico A-B evidenciando a posição aproximada da paleosuperfície associada às coberturas sedimentares a partir da qual se deu a incisão cenozoica (linha pontilhada). 


\section{Caracterização da área de estudo}

A área de estudo possui uma extensão de aproximadamente $181296 \mathrm{~km}^{2}$ e é delimitada pelas coordenadas geográficas de $19,4^{\circ}$ e $22,9^{\circ}$ de latitude sul e $43,5^{\circ}$ e $48^{\circ}$ de longitude oeste (Figura 1).

A alta/média bacia do Rio Grande e as áreas adjacentes da alta bacia do Rio São Francisco estão localizadas no contato entre a borda sul do Cráton do São Francisco e a zona de interferência entre os orógenos Brasília (NNW-SSE) e Ribeira (NE-SW), ambos desenvolvidos durante a Orogenia Brasiliana, ocorrida no Neoproterozoico (TROUW et al., 2013; HEILBRON et al., 2017a). A região inclui rochas cristalinas do embasamento paleoproterozoico-arqueano, metassedimentos proterozoicos dos grupos São João del Rei, Carandaí, Andrelândia, Araxá e Canastra, além das unidades granulítica, diatexítica e migmatítica da Nappe Socorro-Guaxupé, também neoproterozoicas (CAMPOS NETO et al., 2004; HEILBRON et al., 2017a). Ao norte ocorre cobertura neoproterozoica composta pela alternância entre rochas sedimentares siliciclásticas e carbonáticas pertencentes ao Grupo Bambuí (ALKMIM \& MARTINS-NETO, 2012).

No oeste, próximo ao limite entre os estados de Minas Gerais e São Paulo ocorrem rochas da Bacia do Paraná, representadas por sequências sedimentares do Devoniano ao Jurássico e sequências vulcânicas com predomínio de basaltos. Os basaltos são parcialmente recobertos por rochas psamíticas da Bacia Bauru, preenchida em condições semiáridas a desérticas durante o Neocretáceo (MILANI et al., 2007). Entre o Neocretáceo e Eoceno ocorre magmatismo alcalino na província Minas-Goiás, que se desenvolveu sobre a Faixa Brasília (NW-SE), e no Lineamento magmático de Cabo Frio, ao longo de uma grande zona de fratura de direção WNW-SSE (RICCOMINI et al., 2005). Destacam-se as intrusões alcalinas neocretáceas de Poços de Caldas, Passa Quatro e Itatiaia. Sedimentos paleogênicos e neogênicos ocorrem de maneira restrita, com destaque para a bacia de Aiuruoca (SANTOS, 1999) e para as bacias do "Rift de São João Del Rei" (SAADI, 1991). Os principais registros quaternários correspondem a sedimentos fluviais dispostos em planícies e terraços.

A alta/média bacia do Rio Grande e áreas adjacentes abrangem parte de três unidades de relevo definidas por Ross (2016) em escala continental. De leste para oeste as três unidades são as seguintes: "Planaltos e serras do Atlântico Leste-Sudeste", "Depressão periférica da borda leste da Bacia do Paraná" e "Planaltos e chapadas da Bacia do Paraná". A primeira das unidades citadas ocupa toda a área sobre rochas cristalinas e pode ser simplificadamente dividida entre a Serra da Mantiqueira, situada a SSE e Planalto do Alto Rio Grande, a NNW. Na Serra da Mantiqueira predominam altitudes superiores a $1200 \mathrm{~m}$ e os pontos culminantes se aproximam de $2800 \mathrm{~m}$. Já o Planalto do Alto Rio Grande é formado predominantemente por morros e colinas com altitudes entre 800 e $1100 \mathrm{~m}$, além de algumas cristas quartzíticas que superam os $1200 \mathrm{~m}$ (Figura 1).

Rezende \& Castro (2016) sugerem que a tectônica cenozoica é o principal fator controlador da intensidade da incisão fluvial, com destaque para a Serra da Mantiqueira, onde o soerguimento foi mais intenso e os vales são mais profundos. Soleiras quartzíticas condicionam a ocorrência de áreas colinosas com fraca incisão fluvial, principalmente no setor leste. Por outro lado, a subsidência de depressões tectônicas, notadamente na sub-bacia do Rio Sapucaí, causou uma tendência de encaixamento da drenagem situada a montante. A compartimentação do relevo também é influenciada pelos cinturões de cisalhamento ou zonas de falhas que induzem o grau de fragmentação e as orientações principais do relevo (Saadi 1991). Nesse sentido, se destacam os sistemas transcorrentes do Paraíba do Sul (ENE) e de Campo do Meio (WNWESE).

O clima é tropical de altitude, com verões quentes e chuvosos e invernos frios e secos. A precipitação média anual supera $1800 \mathrm{~mm}$ nos trechos mais elevados da Serra da Mantiqueira e diminui em direção a nordeste para um mínimo de aproximadamente $1400 \mathrm{~mm}$. A temperatura média anual varia entre $12^{\circ} \mathrm{C}$, nas áreas mais altas, $e 20^{\circ} \mathrm{C}$, nas áreas menos elevadas (CARVALHO et al., 2008). A flora nativa é composta predominantemente por Floresta Estacional Semidecidual, enquanto Floresta Ombrófila, Campos e Campos rupestres ocorrem de modo mais restrito (SCOLFORO \& CARVALHO, 2006).

\section{Procedimentos Metodológicos}

Para a identificação de evidências de rearranjos envolvendo as principais linhas de drenagem foi 
utilizada a análise de modelos digitais de elevação (MDE) com resolução espacial de 1 arco-segundo (30 m) produzidos a partir de dados da missão SRTM (Shuttle Radar Topography Mission) (RABUS et al., 2003; FARR et al., 2007). Aos MDEs foram incorporados dados de declividade e de sombreamento do relevo gerados pelo projeto Topodata a partir de dados SRTM refinados (VALERIANO \& ROSSETTI, 2012). A combinação entre essas duas técnicas de visualização e o MDE em escala de cores aumenta o nível de detalhe de alguns elementos de análise do relevo, já que possibilita a adição de aspectos texturais à elevação (TINÓS et al., 2014), além de realçar estruturas geológicas e padrões de drenagens (MAYER, 2000).

Em conjunto com os MDEs foram analisados o arranjo espacial da rede hidrográfica e a disposição desta em relação aos divisores, cristas, escarpamentos, estruturas geológicas, depressões, complexos alcalinos e depósitos sedimentares. Estas análises permitiram a identificação de anomalias, como cotovelos, divisores anomalamente baixos e drenagens transversais (gargantas), bem como a proposição dos mecanismos envolvidos nos rearranjos de drenagem. $\mathrm{O}$ posicionamento das rochas sedimentares da borda leste da Bacia do Paraná (MG/SP) foi utilizado como um potencial marcador da incisão fluvial cenozoica e de mudanças na configuração da rede de drenagem, de forma semelhante ao realizado por Moore \& Larkin (2001) no centro-sul da África. Também foi levada em conta a relação entre a rede hidrográfica e províncias alcalinas neocretáceas que mantiveram os antigos eixos dispersores da drenagem, de modo análogo aos domeamentos causados por plumas do manto referidos por Cox (1989), Moore \& Blenkinsop (2002) e Goudie (2005). Trabalhos de campo com foco na região dos baixos divisores foram realizados para busca de registros sedimentares e conferência das principais feições indicativas de rearranjos de drenagem previamente interpretadas nos trabalhos cartográficos.

Histórias térmicas modeladas através de dados termocronológicos de baixa temperatura (traços de fissão em apatita e (U-Th)/He) em trabalhos prévios (HACKSPACHER et al., 2007; COGNÉ, et al. 2011, 2012; JELINEK et al., 2014; OLIVEIRA, et al. 2016) foram utilizadas como indicadoras dos períodos onde a exumação foi mais intensa. Tais dados são especialmente úteis em áreas caracterizadas pela ausência de marcadores estratigráficos tradicionais
(HIRUMA et al., 2010), como a alta/média bacia do Rio Grande, visto que, conforme atestam Tian et al. (2015), histórias térmicas geradas por termocronologia de baixa temperatura podem ser usadas inclusive para reconstruir a história de incisão fluvial.

\section{Marcos da incisão fluvial cenozoica e posicionamento do antigo divisor Paraná/São Francisco}

Entre as feições que fornecem importantes evidências acerca da evolução da rede de drenagem regional se destaca a Depressão Periférica Paulista, localizada na borda leste da Unidade geotectônica Bacia do Paraná. Esse compartimento corresponde a uma zona deprimida com altitudes de 500 a $700 \mathrm{~m}$, situada entre o Planalto Atlântico, a leste, e as cuestas da Serra Geral, a oeste (AB'SABER, 1969; PINHEIRO \& QUEIROZ NETO, 2014). A escavação dessa depressão exumou rochas paleozoicas na borda oriental da Bacia do Paraná e gerou os boqueirões (percées) nos quais os principais tributários da margem esquerda do Rio Paraná cruzam o front das cuestas e adentram o Planalto Ocidental Paulista. Pouco ao norte, no vale do Rio Grande, ocorre outra zona deprimida análoga à Depressão Periférica Paulista, escavada na Sinformal de Passos: a Depressão Periférica do Rio Grande (Figura 1). As duas depressões são separadas por pequeno remanescente elevado localizado no contato entre rochas da Bacia do Paraná e rochas cristalinas Pré-Cambrianas, ao sul de São Sebastião do Paraíso-MG. O que as diferencia é o fato de que no piso da depressão periférica do Rio Grande afloram rochas pré-cambrianas da Faixa Brasília, enquanto na Depressão Periférica Paulista afloram rochas sedimentares paleozoicas. A relação altimétrica entre as depressões periféricas e as rochas sedimentares situadas nas superfícies cimeiras adjacentes permite estimar taxas de incisão de longo-termo para borda leste/ nordeste da Bacia do Paraná, o que contribui para um melhor entendimento da velocidade em que atuam os processos geomorfológicos na região.

Os marcadores mais antigos da incisão fluvial na média bacia do Rio Grande são fornecidos pelos sedimentos suprabasálticos da Formação Marília (Grupo Bauru) de idade Neocretácica (MENEGAZZO et al., 2016) e da Formação Itaqueri, atribuída ao Paleógeno (MELO \& PONÇANO 1983; RICCOMINI, 1997; MENEGAZZO et al., 2016). O posicionamento dessas unidades permite inferir de forma aproximada 
a provável superfície deposicional a partir da qual se deu a incisão cenozoica na borda leste da Bacia do Paraná (Figura 1C). A essa tentativa de reconstruir posições pretéritas do nível de base regional com base nas mais antigas evidências disponíveis devem ser feitas duas ponderações principais: 1) os remanescentes atualmente expostos das formações Marília e Itaqueri não correspondem ao topo original de ambas, já que elas não permaneceram totalmente imunes aos processos denudacionais; 2) possíveis movimentações tectônicas pós-deposicionais entre os remanescentes sedimentares e os vales atuais podem ter acentuado o desnível entre eles. Contudo, não há evidências locais que apontem a existência prévia de uma considerável coluna de rochas sobre as atualmente expostas. Na Serra da Canastra os resistentes quartzitos favoreceram a preservação das rochas sedimentares que os capeiam, já que eles dificultam o recuo de cabeceiras sobre os platôs. Basaltos da formação Serra Geral exercem função semelhante nas cuestas. A proximidade com a área fonte (faixas Brasília e Ribeira) também sugere que a espessura original dos sedimentos não deveria ser tão expressiva. Da mesma forma, os rejeitos estimados de falhas cenozoicas na região não ultrapassam a ordem das dezenas de metros (SARTORI, 2009; CORTES, 2014; SARTORI \& MORALES, 2016). Tais fatos indicam a viabilidade da estratégia proposta como uma forma de estimar a incisão fluvial de longo-termo.

Os arenitos da Formação Marília recobrem metassedimentos proterozoicos que sustentam o setor ocidental da Serra da Canastra (LEITE et al., 2004; CORTES, 2014; PINTO \& SILVA 2014; SIMÕES et al., 2017), a poucos quilômetros da margem direita do Rio Grande, que corre $700 \mathrm{~m}$ abaixo (Figura 1). Trata-se da ocorrência mais oriental e mais elevada (1200 a 1350 m) do Grupo Bauru, que localmente condiciona um relevo tabular no denominado "Chapadão da Zagaia", inserido nos municípios de Sacramento e São Roque de Minas. Na borda oeste da Serra da Canastra, Cortes (2014) relata avançado estado de alteração intempérica dessa formação. De acordo com Menegazzo et al. (2016), sua idade é Neomaastrichtiana (70,6 a 65,5 $\mathrm{Ma}$ ), o que resultaria em uma taxa de incisão/denudação média de aproximadamente $10 \mathrm{~m} / \mathrm{Ma}$ na depressão do Rio Grande, considerando um entalhamento mínimo de $700 \mathrm{~m}$ (Tabela 1).

Já os remanescentes da Formação Itaqueri encontram-se mapeados nos topos do Planalto de Franca, localizado na margem esquerda do Rio Grande, poucos quilômetros a jusante da garganta onde o rio adentra o domínio da Bacia do Paraná (LEITE et al., 2004) (Figura 1). Em suas cotas mais elevadas estão associadas à ferricretes (LADEIRA \& ROSSETTO, 2016) que certamente favoreceram sua preservação. Localmente foram denominados "Formação Franca" por Perdoncini et al. (2001) e Perdoncini (2003). Os depósitos de leques aluviais da Formação Itaqueri, de ampla distribuição na borda superior das cuestas (MELO \& PONÇANO, 1983; RICCOMINI, 1997; MENEGAZZO et al., 2016), constituem o marcador mais seguro do início da escavação da depressão periférica, já que seu posicionamento demanda a antiga existência de uma área fonte mais elevada a leste, onde hoje ocorre a depressão. Essa área, hoje escavada, se conectava altimetricamente com a borda ocidental do planalto cristalino, originalmente já soerguido em relação à Bacia do Paraná. A idade da Formação Itaqueri ainda é alvo de incertezas, já que não há registro fóssil (MENEGAZZO et al.2016). Porém, as idades a ela atribuídas variam entre o Maastrichtiano-Paleoceno Inferior (MENEGAZZO et al., 2016), o Paleoceno-Eoceno (RICCOMINI, 1997), o Eoceno (MELO \& PONÇANO, 1983) e o Mioceno (PERDONCINI, 2003). A idade paleocênica aparenta ser a mais coerente, pois a deposição dos leques aluviais demandaria a existência de área fonte ainda elevada a leste/nordeste mesmo após a deposição da Formação Marília. Provavelmente a área fonte estaria vinculada aos remanescentes do Soerguimento do Alto Paranaíba (SAP) (PERDONCINI, 2003), contemporâneo ao magmatismo alcalino do Neocretáceo (HASUI, 2010; MENEGAZZO et al., 2016).

Tomando como base a idade Paleogênica (66 a $56 \mathrm{Ma})$ e a altitude máxima de $1060 \mathrm{~m}$ da Formação Itaqueri na margem esquerda do Rio Grande chegase a uma taxa de incisão aproximada entre 8 e $9 \mathrm{~m} /$ Ma (Tabela 1). Essa taxa é muito próxima daquela calculada com base na Formação Marília, o que sugere que a utilização de ambas as formações como marcos geomorfológicos é razoavelmente consistente, apesar de apresentar as limitações já expostas. As taxas de longo-termo encontradas também são compatíveis com aquelas mensuradas em grandes rios da África Ocidental por Grimaud et al. (2014).

O perfil topográfico da Figura $1 \mathrm{C}$ evidencia a existência de uma paleosuperfície balizada pelos remanescentes das coberturas sedimentares pós- 
basálticas a partir da qual se deu a incisão fluvial no Cenozoico. Essa paleosuperfície é contemporânea à Superfície Sul Americana, identificada por Valadão $(1998,2009)$ no Brasil Oriental, e cuja altimetria na alta bacia do Rio São Francisco chega a 1300 m. A Superfície Sul Americana foi elaborada notadamente após o encerramento da sedimentação nas bacias do
Paraná e Sanfranciscana e tem como característica comum a presença de mantos de alteração profundos e encrostamentos lateríticos (VALADÃO, 2009), estes últimos também registrados na Serra da Canastra (VALADÃO, 1998; CORTES, 2014) e no Planalto de Franca (PERDONCINI, 2003; LADEIRA \& ROSSETTO, 2016).

Tabela 1: Taxas de incisão de longo-termo aproximadas no médio curso do Rio Grande estimadas a partir do posicionamento das formações Marília e Itaqueri.

\begin{tabular}{c|c|c|c|c}
\hline Unidade litológica & Idade (Ma) & $\begin{array}{c}\text { Altitude } \\
\text { máxima (m) }\end{array}$ & $\begin{array}{c}\text { Desnível do topo } \\
\text { em relação ao } \\
\text { Rio Grande (m) }\end{array}$ & $\begin{array}{c}\text { Taxa de incisão } \\
\text { aproximada (m/ } \\
\text { Ma) }\end{array}$ \\
\hline Formação Marília & 65,5 a 70,6 & 1350 & 700 & 10 \\
\hline Formação Itaqueri & 56 a 66 & 1060 & 510 & 8 a 9 \\
\hline
\end{tabular}

Fontes: Idades obtidas em Menegazzo et al. (2016), Riccomini (1997) e Melo e Ponçano (1983).

Além de permitir o cálculo de taxas de incisão aproximadas e de estabelecer uma idade máxima do início da abertura das depressões periféricas, o posicionamento das formações Marília e Itaqueri também permite, juntamente com outras evidências, reconstruir a posição aproximada do divisor ancestral que separava as bacias hidrográficas dos rios Paraná e São Francisco. No oeste de Minas Gerais o divisor coincidia com o Soerguimento Alto Paranaíba, uma feição tectônica e orográfica que separava as bacias sedimentares do Paraná/Bauru, a oeste, e Sanfranciscana, a leste (CAMPOS \& DARDENNE, 1997; SGARBI et al., 2001, PERDONCINI, 2003; MENEGAZZO et al., 2016). Portanto, no Neocretáceo não havia conexão entre a rede hidrográfica das duas bacias subsidentes que acolhiam respectivamente a deposição dos grupos Bauru e Mata da Corda. Os corpos vulcânicos mesozoicos localizados na Faixa Brasília constituíam os trechos mais elevados da borda soerguida da Bacia do Paraná (SGARBI et al., 2001; HASUI, 2010) e ainda hoje se sobressaem altimetricamente mesmo após significativa exumação (AMARAL et al., 1997; COGNÉ et al., 2011; DORANTI-TIRITAN et al., 2014). As elevações remanescentes do SAP, pertencentes à província alcalina Minas-Goiás, se conectam ao sul do vale do Rio Grande com o setor ocidental da Serra da Mantiqueira, inserido na província alcalina do Lineamento Magmático de Cabo Frio de direção WNW-SSE. A fonte de calor do magmatismo alcalino em ambas as províncias estaria relacionada a plumas do manto (RICCOMINI et al., 2005), o que corrobora o papel das plumas na gênese de soerguimentos que atuam como dispersores da drenagem (COX, 1989; MOORE \& BLENKINSOP, 2002 e GOUDIE, 2005).

Portanto, todos os indícios apontam que no início do Cenozoico o protodivisor seguia um alinhamento de direção geral NNW-SSE entre os complexos alcalinos neocretáceos de Serra Negra e Tapira, ao norte, e Poços de Caldas, ao sul (Figuras 1A e 2A). Essa continuidade do divisor é atestada tanto pela distribuição dos sedimentos de leques aluviais das Formações Marília e Itaqueri, a oeste, quanto pela natural proeminência das intrusões alcalinas.

Por outro lado, o divisor meridional da bacia do Rio Grande se estabeleceu na Serra da Mantiqueira em uma posição próxima da atual pelo menos desde o Eoceno, concomitante à instalação do "Rift Continental do Sudeste do Brasil". A presença de sedimentos paleogênicos e neogênicos nas bacias de Taubaté e Resende, a SSE da Mantiqueira (RICCOMINI et al., 2004), e na bacia de Aiuruoca, a NNW (SANTOS, 1999), indicam que a serra permaneceu elevada e funcionou como área fonte durante a maior parte do Cenozoico. O soerguimento da Serra da Mantiqueira, correspondente a ombreira NNW do rifte, gerou basculamento do planalto do alto Rio Grande para NNW (SAADI, 1991), condicionando, assim, uma natural direção de escoamento das principais drenagens rumo ao Cráton do São Francisco, topograficamente deprimido em relação aos remanescentes soerguidos das faixas Brasília e Ribeira (Figuras 1A e 2A). A primeira em função das intrusões alcalinas e a segunda em função 
tanto das intrusões quanto do soerguimento do horst da Mantiqueira. A expressão morfológica como terrenos baixos e a presença dos principais sistemas fluviais em seu interior são algumas das características típicas dos crátons no continente sul-americano (HEILBRON et al., 2017b). A Figura 2A ilustra uma proposta de reconstituição da rede de drenagem regional entre o Paleoceno e o Eoceno.

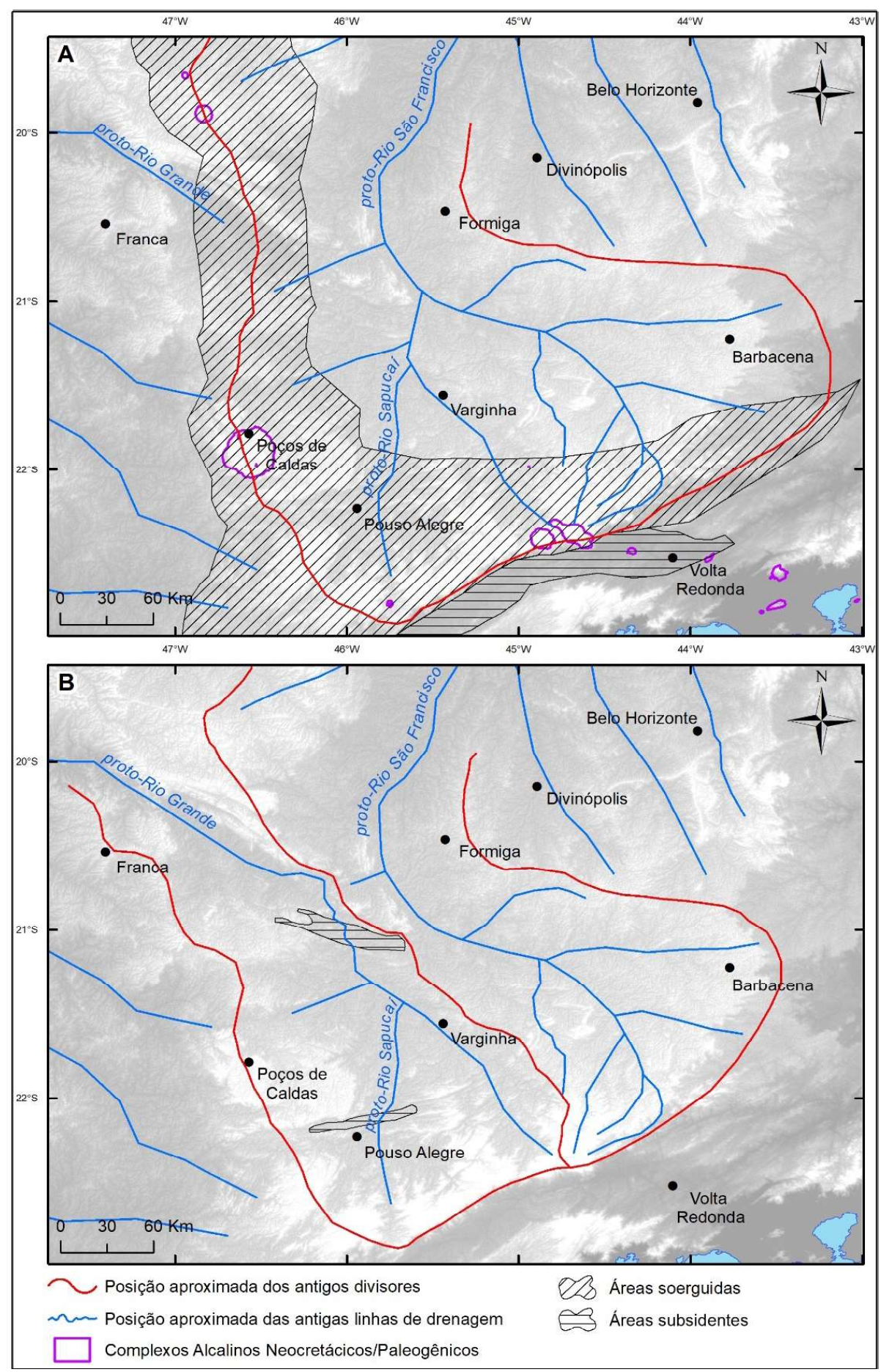

Figura 2 - Provável configuração da rede de drenagem regional em dois momentos diferentes do Cenozoico. A) Paleoceno/Eoceno; B) Mioceno Médio/Superior. A figura 2 A mostra a localização das áreas soerguidas associadas às províncias alcalinas Neocretáceas e ao horst $N N W$ do "Rift Continental do Sudeste do Brasil", além da área subsidente relacionada ao início do preenchimento das bacias de Taubaté, Resende e Volta Redonda. A Figura 2B mostra a localização das áreas subsidentes associadas aos grabens neocenozoicos de Campo do Meio e Pouso Alegre, provavelmente gerados no Mioceno. Fontes: Complexos alcalinos retirados de Leite et al. (2004) e Pinto e Silva (2014). 


\section{Evolução da Rede de Drenagem e Evidências de Antigas Conexões entre as Bacias dos Rios}

Com o início da escavação da depressão periférica houve um progressivo rebaixamento do nível de base que favoreceu o recuo erosivo de um proto-Rio Grande rumo a leste, rompendo assim o divisor ancestral inserido no SAP. As áreas então pertencentes a uma protobacia do Rio São Francisco foram incorporadas à bacia do Rio Paraná através de rearranjos de drenagem (Figura 2B). A incisão fluvial durante o desenvolvimento da depressão periférica do Rio Grande certamente foi favorecida pelas estruturas NW-SE da Faixa Brasília na Nappe de Passos, com as quais o rio mantém paralelismo em boa parte do trecho.

Deste modo, o conjunto de evidências citado sugere que a área atualmente drenada pelo alto Rio Grande pertencia, pelo menos até o Paleógeno, a uma protobacia do Rio São Francisco abrigada no cráton homônimo e com cabeceiras nos soerguimentos do Alto Paranaíba (NNW-SSE) e Mantiqueira (ENE-WSW), conforme mostra a Figura 2.

\section{Anomalias de drenagem e antigas conexões entre as bacias dos rios Grande e São Francisco}

O divisor hidrográfico entre as bacias dos rios Grande e São Francisco apresenta duas notáveis anomalias altimétricas na região sudoeste de Minas Gerais. Tais anomalias consistem em trechos nos quais ele encontra-se em um nível altimétrico muito inferior ao das áreas interfluviais adjacentes. O referido divisor está na sua maior parte situado acima de $1000 \mathrm{~m}$ e em alguns trechos atinge cotas superiores a $1300 \mathrm{~m}$, como nas serras da Canastra, da Pimenta e da Galga. Em geral, o limite entre as bacias dos rios Grande e São Francisco assume forma serrana, como é comum nos interflúvios que delimitam grandes bacias hidrográficas, principalmente as do sudeste brasileiro. No entanto, nos trechos anômalos a altitude é predominantemente inferior a $900 \mathrm{~m}$ e em diversos pontos atinge cotas abaixo de $800 \mathrm{~m}$, o que torna o divisor praticamente imperceptível na paisagem (Figuras 3, 4 e 5A).

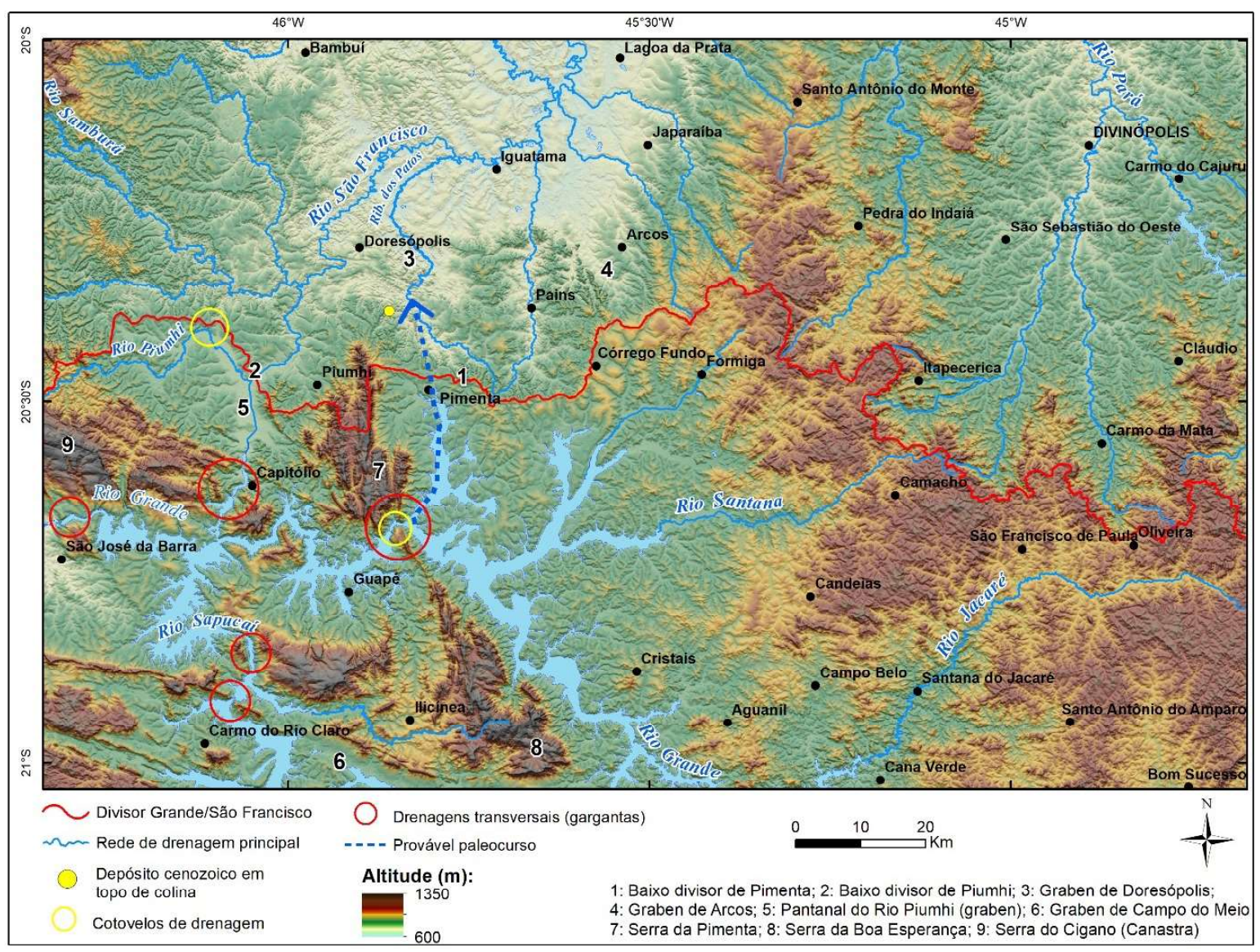

Figura 3 - Modelo digital de elevação da área do divisor hidrográfico entre as bacias dos rios Grande e São Francisco com identificação das principais feições. A seta azul indica o posicionamento aproximado da drenagem que conectava as duas bacias.

Observação: Aqui se destaca que a representação do divisor Grande/São Francisco corresponde ao seu traçado original, desconsiderando a mudança provocada pela transposição das águas do Rio Piumhi, realizada em 1963 quando foi construída a barragem de Furnas (a oeste na figura). 


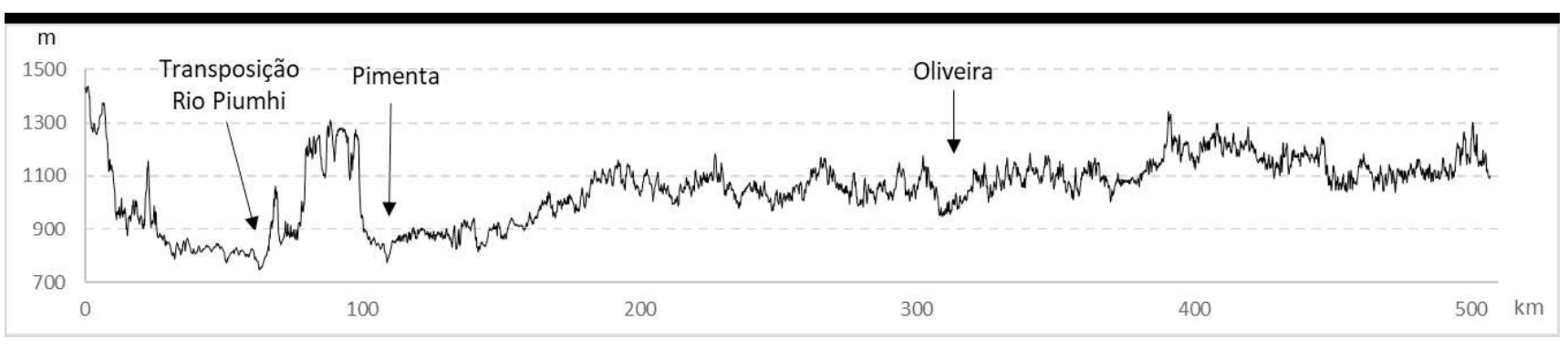

Figura 4-Perfil topográfico de direção geral W-E ao longo de parte do divisor hidrográfico entre as bacias dos rios Grande e São Francisco. Perfil entre os municípios de Vargem Bonita e Carandai.

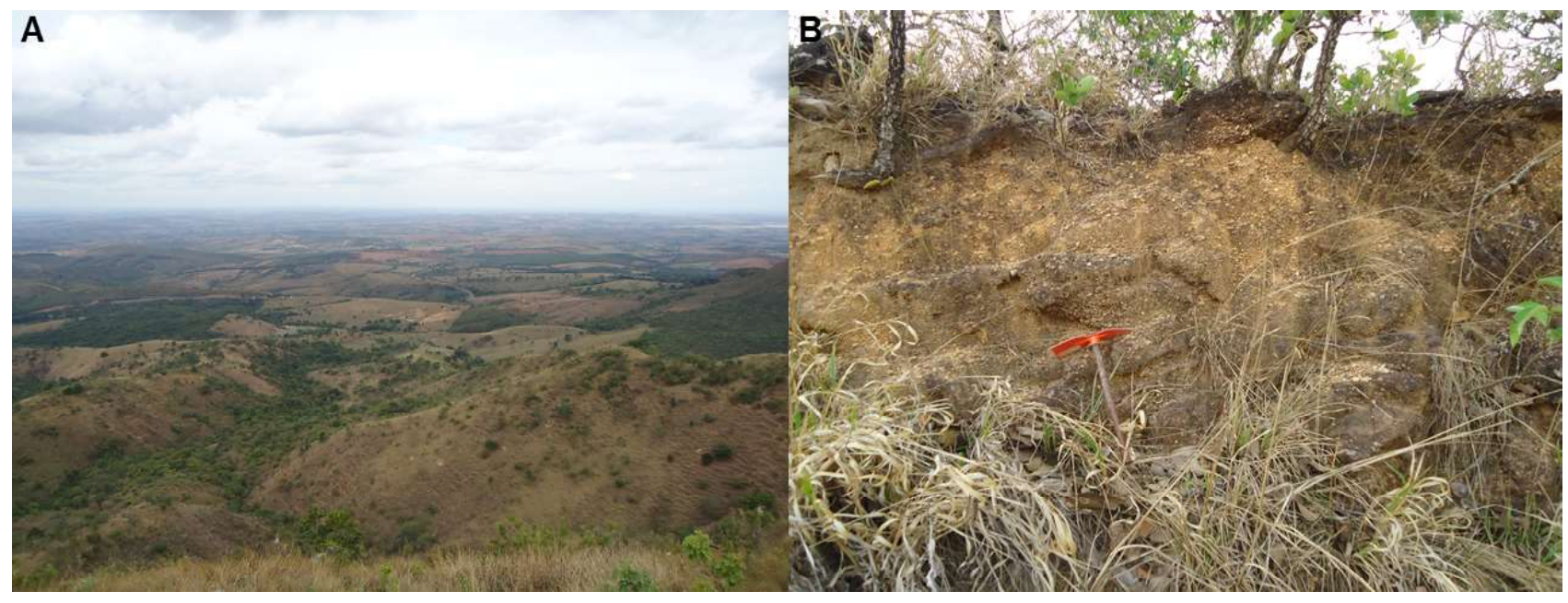

Figura 5-A) Aspecto do baixo divisor entre as bacias dos rios Grande e São Francisco visto a partir da Serra da Pimenta em direção a ENE. B) Depósito aluvial situado em topo de colina (790 m de altitude) a $14 \mathrm{~km}$ a NNW de Pimenta, onde se encontra o baixo divisor hidrográfico.

O primeiro desses trechos anômalos está situado entre os municípios de Pimenta/MG e Córrego Fundo/ MG, totalizando cerca de $40 \mathrm{~km}$ de extensão que acompanham parcialmente o traçado da rodovia MG050 (Figura 3, 4 e 5A). Seu limite ocidental é abrupto e coincide com a escarpa leste da Serra da Pimenta, sustentada por quartzitos da Formação Serra da Boa Esperança. Já o limite oriental é gradual e guarda relação com o contato entre as rochas sedimentares do Grupo Bambuí e metagranitoides arqueanos. O trecho mais baixo está situado a norte da cidade de Pimenta, a apenas $775 \mathrm{~m}$ de altitude, em um nível bastante próximo daquele verificado no Rio Grande (cerca de $740 \mathrm{~m}$ ), situado poucos quilômetros a sul.

A leste dessa área rebaixada, o conjunto de elevações de direção geral E-W que abriga o divisor sofre brusca inflexão para norte, em direção ao município de Santo Antônio do Monte. No entanto, essa inflexão não é acompanhada pelo divisor principal, que mantem sua direção geral E-W e perde altitude, como já mencionado (Figura 3). Atualmente, esse alinhamento de direção N-S atua como interflúvio entre o Rio São Francisco e seu primeiro grande afluente de margem direita, o Rio Pará. No entanto, a sua conexão espacial e semelhança morfológica com o trecho elevado do divisor Grande/São Francisco sugerem que, na verdade, estas elevações constituíam uma antiga continuidade deste divisor para norte. Em outros termos, a estrutura morfológica da região assemelha-se a uma grande bacia hidrográfica delimitada por serras e drenada por cursos fluviais direcionados ao Rio São Francisco (Figuras 1 e 3). No entanto, essa estrutura típica de uma única bacia hidrográfica está, na atualidade, dividida em duas: ao norte situa-se a do São Francisco e a sul a do Rio Grande.

Reforçam essas observações as anomalias de drenagem associadas ao Rio Grande logo ao sul/ sudoeste de Pimenta/MG em área ocupada pela represa de Furnas (Figura 3). Próximo à vila de Santa Hilário há uma mudança brusca na direção geral do Rio 
Grande de NNW para W, formando um cotovelo. Tal mudança ocorre no ponto em que o rio cruza a Serra da Pimenta, em uma típica drenagem transversal. Um prolongamento hipotético do curso do Rio Grande para NNW, a montante da garganta, atingiria exatamente o ponto mais baixo do atual divisor Grande/São Francisco, na região de Pimenta (Figura 3). Além disso, há de se ressaltar que alguns pequenos cursos fluviais localizados nas proximidades do baixo divisor de Pimenta se orientam inicialmente em direção a norte, ou seja, em direção à bacia hidrográfica do Rio São Francisco. Porém, através de cotovelos de drenagem as mesmas mudam abruptamente de direção e infletem para sul em direção ao Rio Grande.

O conjunto de evidências morfológicas citadas sugere uma antiga conexão entre o atual alto curso do Rio Grande e o Rio São Francisco, assim como já proposto com base no posicionamento do antigo divisor São Francisco/Paraná junto a borda leste da Bacia do Paraná/Bauru. Este provável paleovale passaria pela região de Pimenta, antes de ter sido capturado pelo atual médio curso do Rio Grande, explicando assim o anômalo trecho pouco elevado do atual divisor Grande/ São Francisco. A Figura 3 ilustra o posicionamento aproximado do paleovale que conectava as duas bacias.

Registros sedimentares cenozoicos são escassos na região, o que dificulta qualquer tentativa de associá-los a um antigo sistema fluvial que faria a ligação entre o atual alto curso do Rio Grande e o Rio São Francisco. Entre as três ocorrências mapeadas na região de Pimenta (RIBEIRO et al., 2007), apenas uma poderia ser um registro de uma antiga rede de drenagem devido a sua localização e altitude. Este depósito com cerca de $150 \mathrm{~m}$ de extensão está localizado no topo de uma colina, entre 803 e $810 \mathrm{~m}$ de altitude e $14 \mathrm{~km}$ a NNW de Pimenta (Figuras 3 e 5B). É composto por seixos pequenos de quartzo, subarredondados a subangulosos, bem selecionados, em matriz arenosa e parcialmente cimentados por material ferruginoso na forma de couraça conglomerática (Figura 5B). No entanto, o grau de arredondamento relativamente baixo dos clastos e o fato de ser até o momento a única ocorrência identificada dificultam sua utilização na reconstrução da rede de drenagem em escala regional.

O relevo a norte deste trecho do divisor, pertencente à bacia do Rio São Francisco, é nitidamente mais dissecado do que a área a sul, incorporada à bacia do
Rio Grande (Figura 3). Atualmente, o Rio São Francisco estabelece um nível de base regional mais baixo do que o definido pelo Rio Grande na represa de Furnas. Enquanto o primeiro atinge $630 \mathrm{~m}$ na região de Lagoa da Prata, ainda em seu alto curso, o segundo tem seu leito posicionado a aproximadamente $740 \mathrm{~m}$ sob a represa. A princípio, essas observações contradizem a hipótese de que o Rio Grande (atual médio curso) tenha sido o capturador de um antigo alto curso do Rio São Francisco. No entanto, esta configuração geomorfológica está relacionada a um aprofundamento mais recente da rede de drenagem, que localmente pode ter entre suas causas um rebaixamento do nível de base provocado pela geração dos pequenos grabens de Doresópolis e de Arcos, identificados por Saadi (1991). O médio curso do Ribeirão dos Patos, que tem suas cabeceiras no baixo divisor de Pimenta, está inserido no Graben de Doresópolis de direção N40W, a cerca de 660 m de altitude. O recente rebaixamento do nível de base no Alto São Francisco também é atestado pelas duas gerações de condutos cársticos suspensos nos maciços calcários (SAADI et al., 1998). Por outro lado, o Rio Grande, passa imediatamente a jusante do cotovelo de captura, por uma série de soleiras quartzíticas que certamente impuseram maior resistência ao entalhamento quando comparadas às rochas sedimentares drenadas pelos afluentes do atual alto Rio São Francisco. O fato da garganta do Rio Grande na Serra da Pimenta ser bastante ampla lateralmente (mais de $300 \mathrm{~m}$ ) também indica um processo de reorganização da drenagem antigo o suficiente para permitir o ajuste e alargamento dessa feição. Deste modo, atualmente há uma tendência que canais de cabeceira afluentes do Rio São Francisco recuperem, pouco a pouco, por decapitação, parte da área adjacente ao divisor.

O segundo trecho anômalo do divisor Grande/São Francisco está situado a oeste da Serra da Pimenta e, grosso modo, acompanha a margem esquerda do Rio Piumhi (Figuras 1 e 3). Seu limite ocidental é dado pelos contrafortes da Serra da Canastra. Trata-se de um trecho com aproximadamente $25 \mathrm{~km}$ de extensão em altitudes sempre inferiores a $850 \mathrm{~m}$. O ponto mais baixo encontra-se a menos de $750 \mathrm{~m}$ de altitude e foi aproveitado para a realização da transposição das águas do Rio Piumhi na década de 60 (MOREIRA-FILHO \& BUCKUP, 2005). Atualmente a área drenada pelo Rio Piumhi tem suas águas direcionadas para o canal 
do Ribeirão Água Limpa, que por sua vez desagua no Ribeirão Sujo e posteriormente no Rio São Francisco. Ou seja, a transposição provocou uma mudança no posicionamento funcional do divisor de águas, que hoje se encontra mais ao sul.

Nesta área destacam-se ainda duas anomalias relacionadas à rede de drenagem conforme mostra a Figura 3. A primeira é uma inflexão de $90^{\circ}$ no curso do Rio Piumhi, que muda bruscamente sua direção de NE para SE. Esse cotovelo pode indicar uma antiga ligação do Rio Piumhi com o alto curso do Rio São Francisco. A segunda é a presença de uma extensa planície aluvial que acompanha o curso do Rio Piumhi a montante de Capitólio/MG. Essa planície apresenta mais de $3 \mathrm{~km}$ de largura em alguns pontos e era ocupada por um pântano antes da transposição. Suas dimensões demasiadamente desproporcionais ao canal do Rio Piumhi sugerem fortemente um condicionamento tectônico em sua gênese. Esse provável controle tectônico estaria relacionado ao soerguimento de um alinhamento de cristas que é atravessado pelo Rio Piumhi e limita a área pantanosa ao sul. Essas cristas coincidem com a "Rampa Lateral de Capitólio", uma zona transcorrente de direção NW-SE (VALERIANO et al., 2007), cuja reativação neocenozoica pode ter provocado o barramento parcial do Rio Piumhi.

Apesar de não ser possível reconstituir com precisão o antigo posicionamento do Rio Sapucaí é bastante provável que seu ancestral tenha sido incorporado à bacia hidrográfica do Rio Paraná anteriormente ao ancestral do atual alto Rio Grande, devido a sua posição mais ocidental e, portanto, mais próxima do antigo divisor Paraná/São Francisco (Figura 2B). Este fato pode ser uma das causas do predomínio de menores altitudes (<950 m) na bacia do Rio Sapucaí em relação à bacia do alto Rio Grande (Figura 1). Uma possibilidade é que o Rio Sapucaí tivesse seu baixo curso originalmente direcionado para norte ou nordeste, aproveitando-se, em parte, da Zona de Cisalhamento de Campo do Meio e confluindo com o atual Rio Grande a montante da Serra da Pimenta. A gênese do graben de Campo do Meio no Neocenozoico (MORALES, 2005) pode ter contribuído para mudança no baixo curso do Rio Sapucaí e consequentemente na sua interceptação anterior à captura do antigo alto curso do Rio São Francisco (Figura 2B).

Além das evidências geomorfológicas, antigas conexões entre as bacias dos rios Grande e São
Francisco também são sugeridas por estudos genéticos envolvendo espécies de peixes na região dos divisores altimetricamente anômalos (BELLAFRONTE et al., 2010; LUI et al., 2012; PERES et al., 2012). No entanto, estes estudos apontam que nas cabeceiras do Rio São Francisco existem espécies endêmicas que não estão presentes no Rio Grande, o que demonstra que essas ligações foram bastante antigas a ponto de permitir o posterior desenvolvimento de tais espécies.

\section{Eventos tectônicos, superimposição da drenagem e cronologia da denudação}

Na Bacia do Paraná, a sudoeste do SAP, a idade máxima do estabelecimento da rede de drenagem atual tem como marco o início da escavação da depressão periférica após o Paleoceno, quando cessa a sedimentação da Formação Itaqueri (PINHEIRO \& QUEIROZ NETO, 2014). No entanto, os períodos posteriores onde a denudação foi mais intensa, associada à abertura das depressões e aos rearranjos de drenagem, não podem ser bem delimitados através dos registros sedimentares cenozoicos, especialmente na área cristalina a leste/nordeste da Bacia do Paraná, onde sua escassez é mais notável. Deste modo, a utilização de histórias térmicas modeladas através de dados termocronológicos de baixa temperatura (TFAe (U-Th)/ $\mathrm{He})$ se torna de grande utilidade.

O fato do cotovelo de captura do Rio Grande estar imediatamente a montante de uma garganta na Serra da Pimenta (Figuras 1 e 3 ) indica que o rearranjo de drenagem provavelmente ocorreu associado a um processo de superimposição que, por sua vez, implica em uma denudação de centenas de metros nas áreas adjacentes que não permaneceram como elevações residuais. Deste modo, a identificação nas histórias térmicas de períodos do Cenozoico onde houve significativa exumação pode servir como um indicador cronológico da dissecação da "Superfície Sul-Americana", cujos vestígios encontram-se no topo das serras quartzíticas e das cuestas areníticobasálticas (BRAUN, 1970; PERDONCINI et al., 2001; VALERIANO et al., 2007; VALADÃO, 2009; MARQUES NETO et al., 2011; PINHEIRO \& QUEIROZ NETO, 2014). As superfícies de cimeira sustentadas por quartzitos, em especial, são caracterizadas por taxas de denudação extremamente baixas $(<3 \mathrm{~m} / \mathrm{Ma})$, como já demonstrado através da 


\section{Evolução da Rede de Drenagem e Evidências de Antigas Conexões entre as Bacias dos Rios}

mensuração de isótopos cosmogênicos em regiões de contexto geomorfológico semelhante no Brasil (SALGADO et al., 2007; MORAIS NETO, 2009) e na África do Sul (BIERMAN et al., 2014). No Quadrilátero Ferrífero-MG elevações altimetricamente e morfologicamente semelhantes às serras quartzíticas do sul de Minas Gerais abrigam idades de perfis de intemperismo entre 14 a 67,5 Ma (SPIER et al., 2006; Monteiro et al., 2014), o que confirma que seus topos permaneceram relativamente imunes a processos denudacionais de grande intensidade.

Tanto as cristas quartzíticas quanto as cuestas são seccionadas por diversas drenagens transversais (Figura 1) que evidenciam um processo generalizado de superimposição da drenagem a partir de uma paleosuperfície mais regular, parcialmente associada às coberturas sedimentares pós-basálticas. Com base em dados de campo e da estratigrafia das bacias marginais, Valadão $(1998,2009)$ vincula a interrupção da elaboração da "Superfície Sul-Americana" e sua consequente dissecação a um rebaixamento do nível de base provocado por um soerguimento no Mioceno Médio. Esse soerguimento teve distribuição geográfica generalizada e teria alcançado $550 \mathrm{~m}$ no eixo do Alto Paranaíba, conforme estimativa baseada na diferença altimétrica entre superfícies de aplanamento (VALADÃO, 2009).

A quase totalidade das histórias térmicas de amostras coletadas na bacia do Rio Grande e áreas adjacentes do sudeste brasileiro indicam um rápido resfriamento/exumação no Neógeno, com início a cerca de 15-20 Ma (HACKSPACHER et al., 2007; COGNÉ et al., 2011, 2012; JELINEK et al., 2014; OLIVEIRA et al., 2016). A principal exceção são as histórias térmicas dos maciços alcalinos e de seu entorno imediato que apontam uma notável estabilidade ao longo de todo o Cenozoico após um resfriamento extremamente rápido no Neocretáceo. Durante o Paleógeno boa parte das amostras permaneceu em temperaturas mais ou menos constantes. Nos dados de Cogné et al. (2012) apenas a borda NW da Bacia de Taubaté registra um resfriamento rápido concomitante à formação do "Rift Continental do Sudeste do Brasil".

Essa intensificação dos processos denudacionais durante o Mioceno se vincula a um período onde há aceleração dos esforços compressivos sob regime intraplaca, concomitantemente à fase mais rápida de soerguimento dos Andes (CARNEIRO et al., 2012;
COGNÉ et al., 2013). Nesse período ocorre a deposição do Grupo Barreiras ao longo de praticamente toda faixa costeira brasileira situada ao norte do Rio de Janeiro. Essa sedimentação na forma de rampas detríticas seria, em parte, um reflexo dos eventos de denudação em resposta a pulsos de soerguimento (SAADI et al., 2005). No nordeste brasileiro a datação de óxidos de manganês e ferro indica uma idade mínima de $17.8 \pm$ 1.8 Ma e uma idade máxima de $21.6 \pm 2.2$ Ma para o início da deposição da Formação Barreiras (LIMA et al., 2008). No mesmo contexto ocorre a deposição da Formação Pindamonhangaba na Bacia de Taubaté, a SSE da Serra da Mantiqueira, sob transpressão dextral (COGNÉ et al., 2013).

O Neógeno também marca um fenômeno de reorganização generalizada da rede hidrográfica vinculada ao Rio Paraíba do Sul, com ampliação da sua área de drenagem e, consequentemente, aumento do aporte sedimentar direcionado para Bacia de Campos na margem continental (KARNER \& DRISCOLL, 1999; COBBOLD et al., 2001; RICCOMINI et al. 2010, REZENDE, 2013; OLIVEIRA et al., 2016). Outras capturas de grande porte envolvendo os rios São Francisco e Doce foram situadas por Valadão (1998) no Mioceno. Deste modo, é provável que, assim como as bacias hidrográficas vizinhas, a atual bacia do Rio Grande também tenha passado por importantes modificações em sua rede de drenagem nesse período.

Portanto, o conjunto dos dados indica que a superimposição da drenagem que culminou na captura do antigo alto curso do Rio São Francisco teve seu início ou forte aceleração no Mioceno Médio em resposta a um soerguimento generalizado. Tomando como referência a altitude máxima da Serra da Pimenta $(1280 \mathrm{~m})$ e do depósito aluvial preservado em topo de colina $(810 \mathrm{~m})$ (Figura 3) e considerando-o como um possível registro do antigo sistema fluvial anterior à captura é possível estimar uma incisão local de pelo menos $470 \mathrm{~m}$ desde o rebaixamento do nível de base no Mioceno Médio até o momento da captura. Deste modo é plausível que o rearranjo de drenagem tenha se concretizado apenas no Plioceno ou mesmo no início do Pleistoceno. Contudo, a ausência de registros sedimentares mais significativos impede que considerações cronológicas sejam feitas com maior precisão.

No setor planáltico oriental da bacia do Rio Grande, principalmente na sub-bacia do Rio das Mortes, os efeitos do evento denudacional miocênico 
parecem ter sido mais modestos, já que Carmo \& Vasconcelos $(2004,2006)$ encontraram idades de perfis de intemperismo $\left({ }^{39} \mathrm{Ar} /{ }^{40} \mathrm{Ar}\right)$ entre 10 e $12,7 \mathrm{Ma}$ em topos de colinas. Depósitos de pequenas bacias sedimentares atribuídas ao Mioceno Inferior (Saadi et al. 2002) e até ao Neocretáceo (SAADI et al., 1991) também são encontrados atualmente em posição de alta vertente e de topos nas sub-bacias dos rios das Mortes e Jacaré, respectivamente. A preservação de materiais de idade miocênica ou anterior indica que os processos denudacionais posteriores se restringiram a um modesto decapeamento dos mantos de intemperismo nos topos e a uma incisão de algumas dezenas de metros nos vales. Portanto, no setor leste da bacia do Rio Grande não houve um rebaixamento erosivo generalizado do relevo após o Mioceno Médio, ao contrário do que ocorreu na Serra da Mantiqueira e nos vales da subbacia do Rio Sapucaí, como sugerido pelos dados termocronológicos. $\mathrm{O}$ fato dos registros mais antigos (sedimentos e saprolitos) estarem situados a montante de importantes rupturas de declive nos perfis longitudinais (REZENDE \& CASTRO, 2016) indica que parte considerável da denudação Neogênica está associada a abertura de depressões através do recuo erosivo de knickpoints.

Em algumas das drenagens transversais (water gaps) movimentações tectônicas posteriores ao início da superimposição (SAADI, 1991; COSTA, 1999; FERREIRA, 2001; MAGALHÃES JUNIOR \& TRINDADE 2005; MORALES, 2005; REZENDE \& CASTRO, 2016) podem ter realçado o desnível entre os topos das cristas e os vales sem que isso causasse o barramento total dos cursos fluviais. $\mathrm{Ou}$ seja, um processo de antecedência teria se somado à superimposição na gênese das gargantas. Acumulações aluviais anômalas e/ou escarpas de falha sem controle litológico explícito fornecem indícios morfológicos desse quadro no graben de Campo do Meio, abrigado ao longo da zona de cisalhamento de mesmo nome (WNW-ESE), e nos grabens do Rio Piumhi, de Ijaci, de Pouso Alegre e do Rio das Mortes.

\section{Considerações Finais}

A análise conjunta de registros sedimentares, anomalias de drenagem, eixos de soerguimento e dados termocronológicos apontou diversas evidências de que o atual alto curso do Rio Grande se encontrava previamente direcionado para norte, rumo ao Cráton do São Francisco, onde encontra-se abrigado em sua depressão central o Rio São Francisco. O divisor ancestral entre as duas bacias hidrográficas coincidia com o eixo soerguido de direção geral NNW-SSE ao longo das intrusões alcalinas Neocretáceas que bordejam a nordeste a Unidade geotectônica Bacia do Paraná. A distribuição dos depósitos de leques aluvias das Formações Marília (Neomaastrichtiana) e Itaqueri (Paleoceno) indica a funcionalidade do divisor ancestral pelo menos até o Paleoceno e demanda que a abertura da Depressão Periférica da Bacia do Paraná tenha sido posterior a esse período.

Ao final da deposição da Formação Itaqueri o desgaste erosivo do divisor ancestral provavelmente já o teria rebaixado consideravelmente em relação às altitudes alcançadas durante a manifestação do magmatismo alcalino Neocretáceo. Entre o final da deposição e o Mioceno Médio ocorreu um período de relativa estabilidade tectônica, com taxas denudacionais mais modestas, umidificação do clima e uma tendência de laterização associada ao desenvolvimento da "Superfície Sul-Americana".

Um soerguimento generalizado no Mioceno Médio causou rebaixamento do nível de base e acelerou a abertura das depressões escavadas a partir do contato entre a Bacia do Paraná e as rochas cristalinas PréCambrianas. A superimposição da drenagem associada à dissecação da "Superfície Sul-Americana" promoveu a gênese de diversas gargantas que seccionam as estruturas exumadas da Faixa Brasília e as cuestas arenítico-basálticas na Bacia do Paraná. Aproveitandose da zona de fraqueza ao longo da Sinformal de Passos, um proto-Rio Grande promoveu um intenso recuo erosivo em direção a ESE, concomitante ao aprofundamento da drenagem. Esse processo culminaria na captura do antigo alto curso do Rio São Francisco $\mathrm{e}$, consequentemente, na transferência de uma área de drenagem considerável para a bacia do Rio Paraná. Ressalta-se que a área de drenagem transferida fez com que aquelas regiões e cabeceiras que correspondiam as antigas nascentes do Rio São Francisco e se localizavam na Serra da Mantiqueira se tornassem as do Rio Grande, o principal formador do Rio Paraná. Trata-se, portanto, de uma significativa transferência de área e de nascentes entre duas das cinquenta maiores bacias hidrográficas do mundo.

O baixo divisor anômalo na região de Pimenta- 


\section{Evolução da Rede de Drenagem e Evidências de Antigas Conexões entre as Bacias dos Rios}

MG corresponde a um expressivo registro morfológico do paleovale que conectava as duas bacias atualmente separadas. Poucos quilômetros a SSW do baixo divisor, um notável cotovelo de drenagem marca o ponto de captura. Taxas médias de incisão de longo-termo foram estimadas em cerca de $10 \mathrm{~m} / \mathrm{Ma}$, com base no posicionamento das formações Marília e Itaqueri adjacentes ao médio vale do Rio Grande.

\section{Agradecimentos}

Agradecemos à Capes pela bolsa de doutorado do primeiro autor. Agradecemos também a Celina Cenni e Amanda Garcia pelas contribuições.

\section{Referências Bibliográficas}

AB'SÁBER, A. N. O problema das conexões antigas e da separação da drenagem do Paraíba e Tietê. Boletim Paulista de Geografia, n. 26, p. 38-49, 1957.

AB'SÁBER, A. N. A depressão periférica paulista: um setor das áreas de circundesnundação pós-cretácica na bacia do Paraná. Geomorfologia, n. 5, p. 1-15, 1969.

ALKMIM, F. F.; MARTINS-NETO, M. A. Proterozoic firstorder sedimentary sequences of the São Francisco craton, eastern Brazil. Marine and Petroleum Geology, v. 33, n. 1, p. 127-139, 2012.

AMARAL, G.; BORN, H.; HADLER, J. C. N.; IUNES, P. J.; KAWASHITA, K.; MACHADO, D. L.; OLIVEIRA, E. P.; PAULO, S. R.; TELLO, C. A. S. Fission track analysis of apatites from São Francisco craton and Mesozoic alcaline-carbonatite complexes from central and southeastern Brazil. Journal of South American Earth Sciences, v. I, n. 97, p. 285-294, 1997.

BELLAFRONTE, E.; MOREIRA-FILHO, O.; VICARI, M. R.; ARTONI, R. F.; BERTOLLO, L. A. C.; MARGARIDO, V. P. Cytogenetic identification of invasive fish species following connections between hydrographic basins. Hydrobiologia, v. 649, n. 1, p. 347-354, 2010.

BIERMAN, P. R.; COPPERSMITH, R.; HANSON, K.; NEVELING, J.; PORTENGA, E. W.; ROOD, D. H. A cosmogenic view of erosion, relief generation, and the age of faulting in southern Africa. GSA Today, v. 24, n. 9, p. 4-11, 2014.

BISHOP, P. Drainage rearrangement by river capture, beheading and diversion. Progress in Physical Geography, v. 19, n. 4, p. 449-473, 1995.
BRAUN, O. P. Contribuição à geomorfologia do Brasil Central. Revista Brasileira de Geografia, v. 32, n. 3, p. 3-39, 1971.

CAMPOS, J. E. G.; DARDENNE, M. A. Origem e evolução da Bacia Sanfranciscana. Revista Brasileira de Geociências, v. 27, n. 3, p. 283-294, 1997.

CAMPOS NETO, M. C.; BASEI, M. A. S.; VLACH, S. R. F.; CABY, R.; SZABÓ, G. A. J.; VASCONCELOS, P. Migração de Orógenos e Superposição de Orogêneses: Um Esboço da Colagem Brasiliana no Sul do Cráton do São Francisco, SE Brasil. Geologia USP - Serie Cientifica, v. 4, n. 1, p. 13-40, 2004.

CARNEIRO, C. D. R.; ALMEIDA, F. F. M.; HASUI, Y.; ZALÁN, P. V.; TEIXEIRA, J. B. G. (2012). Estágios evolutivos do Brasil no Fanerozoico. In: HASUI, Y.; CARNEIRO, C. D. R.; ALMEIDA, F. F. M.; BARTORELLI, A. (org.) Geologia do Brasil. Beca, São Paulo: p. 131-137.

CARMO, I. O.; VASCONCELOS, P. Geochronological evidence for pervasive Miocene weathering, Minas Gerais, Brazil. Earth Surface Processes and Landforms, v. 29, n. 11, p. 1303-1320, 2004.

CARMO, I. O.; VASCONCELOS, P. M. ${ }^{40} \mathrm{Ar}{ }^{\beta 9} \mathrm{Ar}$ geochronology constraints on late Miocene weathering rates in Minas Gerais, Brazil. Earth and Planetary Science Letters, v. 241, n. 1-2, p. 80-94, 2006.

CARVALHO, L. G.; OLIVEIRA, M. S.; ALVES, M. C.; VIANELLO, R. L.; SEDIYAMA, G. C.; CASTRO NETO, P.; DANTAS, A. A. A. (2008). Clima. In: SCOLFORO, J. R. S.; CARVALHO, L. M. T.; OLIVEIRA, A. D. (eds). Zoneamento Ecológico-Econômico de Minas Gerais: Componentes geofísico e biótico. Universidade Federal de Lavras, Lavras: p. 89-102.

COBBOLD, P. R, MEISLING, K. E., MOUNT, V. S. Reactivation of an obliquely rifted margin, Campos and Santos basins, southeastern Brazil. AAPG Bulletin, v. 85, n. 11, p.19251944, 2001.

COGNÉ, N.; GALLAGHER, K.; COBBOLD, P. R. Post-rift reactivation of the onshore margin of southeast Brazil: Evidence from apatite $(\mathrm{U}-\mathrm{Th}) / \mathrm{He}$ and fission-track data. Earth and Planetary Science Letters, v. 309, n. 1-2, p. 118-130, 2011.

COGNÉ,N.; GALLAGHER, K.; COBBOLD, P. R.; RICCOMINI, C.; GAUTHERON, C. Post-breakup tectonics in southeast Brazil from thermochronological data and combined inverse-forward thermal history modeling. Journal of Geophysical Research: Solid Earth, v. 117, n. 11, p. 1-16, 2012. 
COGNÉ, N.; COBBOLD, P. R.; RICCOMINI, C.; GALLAGHER, $\mathrm{K}$. Tectonic setting of the Taubaté Basin (Southeastern Brazil): Insights from regional seismic profiles and outcrop data. Journal of South American Earth Sciences, v. 42, p. 194-204, 2013.

CONTI, L. A. (2012). Paleodrainage Systems. In: JAVAID M.S. (ed.) Drainage Systems. InTech, p.: 3-20.

CORTES, J. P. S. D. Compartimentação e evolução geomorfológica da borda ocidental da Serra da CanastraMG. Dissertação de mestrado, Instituto de Geociências e Ciências Exatas, Universidade Estadual Paulista, Rio Claro. 2014. $116 \mathrm{p}$.

COSTA, R. D. Determinação dos campos de tensão cenozóicos na região sul de Minas Gerais. Tese (Doutorado em Geociências) - Instituto de Geociências e Ciências Exatas, Universidade Estadual Paulista, Rio Claro. 1999. 135p.

COX, K. G. The role of mantle plumes in the development of continental drainage patterns. Nature, v. 342, p. 873-877, 1989.

DORANTI-TIRITAN, C.; HACKSPACHER, P. C.; RIBEIRO, M. C. S.; GLASMACHER, U. A.; SOUZA, D. H. Evolução do relevo da região do planalto de Poços de Caldas (SP/MG) baseado em dados de termocronologia de baixa temperatura e modelagem termocinemática 3D. Revista Brasileira de Geomorfologia, v. 2, p. 291-310, 2014.

FARR, T.; ROSEN, P.; CARO, E.; CRIPPEN, R.; DUREN, R.; HENSLEY, S.; KOBRICK, M.; PALLER, M.; RODRIGUEZ, E.; ROTH, L.; SEAL, D.; SHAFFER, S.; SHIMADA, J.; UMLAND, J.; WERNER, M.; OSKIN, M.; BURBANK, D.; ALSDORF, D. The shuttle radar topography mission. Reviews of Geophysics, v. 45, n. 2005, p. 1-33, 2007.

FERREIRA, M. F. M. Geomorfologia e análise morfotectônica do alto vale do Sapucaí - Pouso Alegre (MG). 2001. 279 f. Tese (Doutorado em Geociências e Meio Ambiente) - Instituto de Geociências e Ciências Exatas, Universidade Estadual Paulista, Rio Claro, 2001.

GALLAGHER, K. (2012). Uplift, denudation, and their causes and constraints over geological timescales. In: ROBERTS D. G.; BALLY A. W. Regional Geology and Tectonics: Principles of Geologic Analysis. Elsevier, p .609-644.

GRIMAUD, J. L.; CHARDON, D.; BEAUVAIS, A.. Very longterm incision dynamics of big rivers. Earth and Planetary Science Letters, v. 405, p. 74-84, 2014.

GOUDIE, A. S. The drainage of Africa since the Cretaceous. Geomorphology, v. 67, n. 3-4, p. 437-456, 2005.

HACKSPACHER, P. C.; GODOY, D. F.; RIBEIRO, L. F.
B.; HADLER NETO, J. C.; FRANCO, A. O. B. Modelagem térmica e geomorfologia da borda sul do Cráton do São Francisco: termocronologia por traços de fissão em apatita. Revista Brasileira de Geociências, v. 37, p. 76-86, 2007.

HASUI, Y. A grande colisão Pré-Cambriana do sudeste brasileiro e a estruturação regional. Geociências - UNESP, v. 29, p. 141-169, 2010.

HASUI, Y. (2012) Sistema Orogênico Mantiqueira. In: HASUI, Y.; CARNEIRO, C. D. R.; ALMEIDA, F. F. M.; BARTORELLI, A. (org.) Geologia do Brasil. Beca, São Paulo: p. 331-610.

HEILBRON, M., RIBEIRO, A., VALERIANO, C. M., PACIULlO, F. V., ALMEIDA, J. C. H., TROUW, R. J. A., SILVA, L. E. (2017a). The Ribeira Belt. In: HEILBRON M.; CORDANi U. G.; ALKMIN F. F. São Francisco Craton, Eastern Brazil. Springer International Publishing, p. 277-302.

HEILBRON, M.; CORDANI, U. G.; ALKMIM, F. F. (2017b). The São Francisco Craton and Its Margins. In: HEILBRON M.; CORDANI U. G.; ALKMIN F. F. São Francisco Craton, Eastern Brazil. Springer International Publishing, 2017. p. 3-13.

HIRUMA, S. T.; RICCOMINI, C.; MODENESI-GAUTTIERI, M. C.; HACKSPACHER, P. C.; HADLER-NETO, J. C.; FRANCO-MAGALHÃES, A. O. B. Denudation history of the Bocaina Plateau, Serra do Mar, southeastern Brazil: Relationships to Gondwana breakup and passive margin development. Gondwana Research, v. 18, p. 674-687, 2010.

JELINEK, A. R.; CHEMALE, F.; VAN DER BEEK, P. A.; GUADAGNIN, F.; CUPERTINO, J. A.; VIANA, A. Denudation history and landscape evolution of the northern East-Brazilian continental margin from apatite fission-track thermochronology. Journal of South American Earth Sciences, v. 54, p. 158-181, 2014.

KARNER, G. D; DRISCOLL, N. W. (1999). Tectonic and stratigraphic development of the West African and eastern Brazilian Margins: insights from quantitative basin modelling. In: CAMERON, N. R., BATE, R. H. \& CLURE, V. S. (eds.) The Oil and Gas Habitats of the South Atlantic. Geological Society, London: Special Publications, v. 153, p. 11-40.

KING, L. C. A Geomorfologia do Brasil Oriental. Revista Brasileira de Geografia, v. 18, n. 2, p. 147-266, 1956.

LADEIRA F. S. B.; ROSSETTO, M. J. B. Superfícies de Cimeira e Perfis de Alteração Associados no Planalto de Franca no Estado de São Paulo. In: $24^{\circ}$ Congresso de Iniciação Científica da Unicamp, 2016, Campinas, Anais. 
Evolução da Rede de Drenagem e Evidências de Antigas Conexões entre as Bacias dos Rios

LEITE, C. A. S.; PERROTTA, M. M.; SILVA, L. C.; SILVA, M. A.; HEINECK, C. A.; SALVADOR, E. D.; VIEIRA V. S., LOPES R. C.; SILVA M.G. M., DRUMOND J. B. V., MALOUF, R. F.; LACERDA FILHO, J. V. (2004). Folha SF-23-Rio de Janeiro. In: SCHOBBENHAUS, C. et al. Carta Geológica do Brasil ao Milionésimo, Sistema de Informações Geográficas. Brasília, CPRM.

LIMA M. G. L, VASCONCELOS P., FARLEY K. SÁ E. F. J. Datação do intemperismo do nordeste oriental do Brasil. Congresso Brasileiro de Geologia. In: $44^{\circ}$ Congresso Brasileiro de Geologia, 44, 2008, Curitiba. Anais... SBG. 2008. p. 285.

LUI, R. L.; BLANCO, D. R.; MARGARIDO, V. P.; KUHN, G. C. e S.; GOMES, V. N.; PRIOLI, A. J.; MOREIRA-FILHO, O. A recent transposition of river involving Paraná and São Francisco basins: Effects on the genetic variability and structure of the neotropical fish Parauchenipterus galeatus (Siluriformes, Auchenipteridae). Mitochondrial DNA, v. 23, n. 5, p. 388-395, 2012.

MAGAlHÃES JUNIOR. A. P.; TRINDADE E. S. Morfodinâmica fluvial cenozóica em zonas de contato entre faixas móveis e "cunhas tectônicas" na região sul de Minas Gerais. Geonomos, v. 13, n. 1 e 2, p. 59-74, 2005.

MARQUES NETO, R.; VIADANA, A. G. Superfícies Geomórficas No Planalto Do Alto Rio Grande (MG): Região Das Cristas Quartzíticas. Revista de Geografia - PPGEO, v. 2, n. 1, p. 1-8, 2011.

MELO M. S.; PONÇANO W. L. Gênese, distribuição e estratigrafia dos depósitos cenozóicos no Estado de São Paulo. São Paulo: IPT, 1983. 75 p.

MENEGAZZO, M. C.; CATUNEANU, O.; CHANG, H. K. The South American retroarc foreland system: The development of the Bauru Basin in the back-bulge province. Marine and Petroleum Geology, v. 73, p. 131-156, 2016.

MILANI, E. J.; FRANÇA, A. B.; S., R. L. Bacia do Paraná. Boletim de Geociências da PETROBRÁS, v. 15, n. 2, p. 265-287, 2007.

MONTEIRO, H. S.; Vasconcelos, P. M.; Farley, K. A.; Spier, C. A.; Mello, C. L. (U-Th)/He geochronology of goethite and the origin and evolution of cangas. Geochimica et Cosmochimica Acta, v. 131, p. 267-289, 2014.

MOREIRA FILHO, O.; BUCKUP, P. A. A poorly known case of watershed transposition between the São Francisco and upper Paraná river basins. Neotropical Ichthyology, v. 3, n. 3 , p. 449-452, 2005.
MOORE, A.; LARKIN, P. Drainage evolution in south-central Africa since the breakup of Gondwana. South African Journal of Geology, v. 104, p. 47-68, 2001.

MOORE, A.; BLENKINSOP, T. The role of mantle plumes in the development of continental-scale drainage patterns: The southern African example revisited. South African Journal of Geology, v. 105, n. 4, p. 353-360, 2002.

MORAIS NETO, J. M. Thermochronology, landscape evolution, denudation history of Eastern Borborema Province, Northeastern Brazil. Tese de doutorado, University of Queensland, Queensland. 2009. 238 p.

MORALES, N. Neotectônica em ambiente intraplaca: exemplos da região sudeste do Brasil. Tese de Livre Docência, Instituto de Geociências e Ciências Exatas, Universidade Estadual Paulista, Rio Claro, 2005. 201 p.

OLIVEIRA, C. H. E.; JELINEK, A. R.; CHEMALE, F.; CUPERTINO, J. A. Thermotectonic history of the southeastern Brazilian margin: Evidence from apatite fission track data of the offshore Santos Basin and continental basement. Tectonophysics, v. 685 , p. 21-34, 2016.

PEDERSON, D. T. Stream Piracy Revisited: A GroundwaterSapping Solution. GSA Today, v. 11, n. 9, p. 4-10, 2001.

PERDONCINI, L.C. Evolução tectono-sedimentar mesozóico-cenozóica da região de Franca. Tese de doutorado, Universidade Estadual Paulista, Rio Claro. 2003. 197 p.

PERDONCINI, L. C.; MORALES, N.; ZANARDO, A.; CARVALHO, S. G.; HASUI, Y.; COSTA, J. B. S.; BORGES M.; RUEDA, J. R. J. (2017). Mesozoic-Cenozoic evolution of diamondiferous province of Franca, São Paulo State, Brazil. Revista Brasileira de Geociências, v. 31, n. 4, p. 665668, 2017.

PERES, W. A. M.; BERTOLlO, L. A. C.; BUCKUP, P. A.; BLANCO, D. R.; KANTEK, D. L. Z.; MOREIRA-FILHO, O. Invasion, dispersion and hybridization of fish associated to river transposition: Karyotypic evidence in Astyanax "bimaculatus group" (Characiformes: Characidae). Reviews in Fish Biology and Fisheries, v. 22, n. 2, p. 519-526, 2012.

PINHEIRO, M. R.; QUEIROZ NETO, J. P. Reflexões sobre a gênese da Serra Geral e da Depressão Periférica Paulista: O exemplo da região da Serra de São Pedro e do Baixo Piracicaba, SP. Revista do Instituto Geológico, v. 35, n. 1, p. 47-59, 2014.

PINTO C. P.; SILVA M. A. Mapa Geológico do Estado de Minas Gerais. Codemig/CPRM, 2014.

RABUS, B.; EINEDER, M.; ROTH, A.; BAMLER, R. The 
shuttle radar topography mission - A new class of digital elevation models acquired by spaceborne radar. ISPRS Journal of Photogrammetry and Remote Sensing, v. 57, n. 4, p. 241-262, 2003.

REZENDE, E. A. Evolução do relevo no divisor hidrográfico entre as bacias dos rios Grande e Paraíba do Sul: um estudo na Serra da Mantiqueira (MG/RJ). Dissertação de Mestrado, Instituto de Geociências, Universidade Federal de Minas Gerais, Belo Horizonte, 2013. 106 p.

REZENDE, E. A.; CASTRO, P. T. A. Variação espacial e condicionantes do entalhamento fluvial na bacia do Rio Grande, sul de Minas Gerais. Revista Brasileira de Geomorfologia, v. 17, n. 4, 2016.

RIBEIRO, A.; PACIUllo, F. V. P.; SENRA, A. S.; VALERIANO, C. M.; TROUW R. A. J. (2007). Piumhi- SF.23V-B-II, escala 1:100.000: nota explicativa. In: CPRM. Geologia da folha Piumhi- SF.23-V-B-II. UFRJ/CPRM, Minas Gerais. $50 \mathrm{p}$.

RICCOMINI, C. Considerações sobre a posição estratigráfica e tectonismo deformador da Formação Itaqueri na porção centroleste do Estado de São Paulo. Revista do Instituto Geológico, v. 18, n. $1 / 2$, p. $41-48,1997$.

RICCOMINI, C; SANT'ANNA, L. G.; FERRARI, A. L. (2004) Evolução geológica do Rift Continental do Sudeste do Brasil. In: MANTESSO-NETO, V.; BARTORELLI, A. CARNEIRO, C. D. R.; BRITO-NEVES, B. B. (eds.). Geologia do continente SulAmericano: evolução da obra de Fernando Flávio Marques de Almeida. Beca, São Paulo: p. 383-405.

RICCOMINI, C.; VELÁZQUEZ, V. F.; GOMES, C. B. (2005). Tectonic controls of the Mesozoic and Cenozoic alkaline magmatism in central-southeastern Brazilian Platform. In: In: COMIN-CHIARAMONTI P., BARROS, C. (eds.). Mesozoic to Cenozoic alkaline magmatism in the brazilian platform. EDUSP/FAPESP, São Paulo: p. 31-56.

RICCOMINI, C.; GROHMANN, C. H.; SANT'ANNA, L. G.; HIRUMA, S. T. (2010). A captura das cabeceiras do Rio Tietê pelo Rio Paraíba do Sul. In: MODENESI-GAUTTIERI, M. C.; BARTORELLI, A.; MANTESSO-NETO, V.; CARNEIRO, C. D. R.; LISBOA, M. B. A. L. (org.). A Obra de Aziz Nacib Ab'Sáber. Beca, São Paulo: p. 157-169.

ROSS, J. L. S. O relevo brasileiro no contexto da América do Sul. Revista Brasileira de Geografia, v. 61, n. 1, p. 21-58, 2016.

SAADI, A. Ensaio Sobre a Morfotectônica de Minas Gerais tensões intra-placa, descontinuidades crustais e morfogênese. Tese (Prof. Titular) - Instituto de Geociências, Universidade
Federal de Minas Gerais, Belo Horizonte, 1991. 285 p.

SAADI, A.; VALADÃO, R. C.; SILVEIRA, J. S. Vulcanismo extrusivo e tectônica cretáceos no centro-sul de Minas Gerais. In: III Simpósio Nacional de Estudos Tectônicos, 3, 1991, Rio Claro. Boletim... SBG. 1991. p. 88-90.

SAADI, A.; MORAIS, M. S.; CARDOSO, G. G. C. Evolução morfotectônica e carstogênese na região de Arcos-painsDoresópolis. Geosul, (Edição especial, Simpósio Nacional de Geomorfologia, 2)., v. 14, n. 27, p. 341-344, 1998.

SAADI, A; MACHETTE, M. N.; HALLER, K. M.; DART, R. L; BRADLEY, L.; SOUZA, A. M. P. D. Map and Database of Quaternary Faults and Lineaments in Brazil. Denver: USGS, 2002. $59 \mathrm{p}$.

SAADI, A.; BEZERRA, F.H.R.; COSTA, R.D.; IGREJA, H.L.S.; FRANZINELLI, E. (2005). Neotectônica da Plataforma Brasileira. In: SOUZA C.R.G.; SUGUIO, K.; OLIVEIRA A.M.S.; OLIVEIRA, P.E. (eds). Quaternário do Brasil. Holos, Ribeirão Preto: p. 211-234.

SAlGADO, A. A. R.; VARAJÃO, C. A. C.; COLIN, F.; FELIPE, L.; CHEREM, S.; MARENT, B. R.; BRINDUSA, C. B. Estimativa das taxas de erosão das terras altas da alta bacia do rio das Velhas no Quadrilátero Ferrífero: implicações para a evolução do relevo. Revista Brasileira de Geomorfologia, v. 8, n. 2, p. 1-8, 2007.

SANTOS, M. Serra da Mantiqueira e Planalto do Alto Rio Grande: a bacia terciária de Aiuruoca e evolução morfotectônica. Tese (Doutorado em Geociências). Instituto de Geociências e Ciências Exatas, Universidade Estadual Paulista, Rio Claro, 1999. 134 p.

SARTORI, J. E. Caracterização estrutural da Zona de Falha de Cássia/MG. Trabalho de Conclusão do Curso, Instituto de Geociências e Ciências Exatas, Universidade Estadual Paulista, Rio Claro. 2009. 42 p.

SARTORI, J. E.; MORALES, N. Reativação de falhas: o caso da zona de falha de Cássia/MG. Holos Environment, Suplemento IX Encontro de Pós-graduação em Geociências e Meio Ambiente, 2016.

SCOLFORO, J. R. S.; CARVALHO, L. M. T. Mapeamento e inventário da flora nativa e dos Reflorestamentos de Minas Gerais. Lavras: IEF/UFLA, 2006. 288 p.

SGARBI, G. N. C.; SGARBI, P. D. A.; CAMPOS, J. E. G.; DARDENNE, M. A.; PENHA, U. C. (2001). Bacia Sanfranciscana: o registro fanerozóico da Bacia do São Francisco. In: PINTO C. P; MARTINS-NETO M. A. Bacia 
do São Francisco: Geologia e Recursos Naturais. SBG-MG, Belo Horizonte: 349 p.

SIMÕES, L. S. A.; SILVA, A. J. C. A.; SILVA, C. H.; VALERIANO, C. M.; LEITE JUNIOR, W. B.; PEREZ, A. I.; HARTUNG, R. F. (2017). Folha Desemboque - SF.23-V-A-II. CODEMIG/UFMG, 107 p.

SPIER, C. A.; VASCONCELOS, P. M.; OLIVIERA, S. M. ${ }^{40} \mathrm{Ar} /{ }^{39} \mathrm{Ar}$ geochronological constraints on the evolution of lateritic iron deposits in the Quadrilátero Ferrífero, Minas Gerais, Brazil. Chemical Geology, v. 234, n. 1-2, p. 79-104, 2006.

TIAN, Y.; KOHN, B. P.; HU, S.; GLEADOW, A. J. W. Synchronous fluvial response to surface uplift in the eastern Tibetan Plateau: Implications for crustal dynamics. Geophysical Research Letters, v. 42, n. 1, p. 29-35, 2015.

TINÓS, T. M.; RIEDEL, P. S.; ZAINE, J. E. Técnicas de visualização de modelos digitais de elevação para o reconhecimento de elementos de análise do relevo. Geociências, v. 33, n. 2, p. 952-967, 2014.

TROUW, R. A J.; PETERNEL, R.; RIBEIRO, A.; HEILBRON, M.; VINAGRE, R.; DUFFLES, P.; TROUW, C. C.; FONTAINHA, M.; KUSSAMA, H. H. A new interpretation for the interference zone between the southern Brasília belt and the central Ribeira belt, SE Brazil. Journal of South American Earth Sciences, v. 48, p. $43-57,2013$.
TWIDALE, C. R. River patterns and their meaning. EarthScience Reviews, v. 67, n. 3-4, p. 159-218, 2004.

VALADÃO, R. C. Evolução de longo termo do relevo do Brasil Oriental: desnudação, superfícies de aplanamentos e soerguimentos crustais. Tese (Doutorado em Geologia). Instituto de Geociências, Universidade Federal da Bahia, Salvador. 1998. 243 p.

VALADÃO, R. C. Geodinâmica de Superfícies de Aplanamento, Desnudação Continental e Tectônica Ativa como condicionantes da Megageomorfologia do Brasil Oriental. Revista Brasileira de Geomorfologia, v.10, n. 2, p. 77-90, 2009.

VALERIANO, C. M.; PEREIRA, R. M.; ALMEIDA, J. C. H; DUARTE, B. P.; RANGEL, C. V. G. T.; ROSSI, A.; GONTIJO, A.; RIBEIRO, A.; NOGUEIRA, J. R.; HEILBRON, M.; CASTRO, C.; FALCÃO T. C.; SILVA, V. G. M. R. (2007). Alpinópolis- SF.23-V-B-V, escala 1:100.000: nota explicativa integrada com Guapé. In: CPRM. Geologia da folha Alpinópolis- SF.23-V-B-V. UERJ/CPRM, Minas Gerais.

VALERIANO, M. M.; ROSSETTI, D. F. Topodata: Brazilian full coverage refinement of SRTM data. Applied Geography, v. 32, n. 2, p. 300-309, 2012.

WILLETT, S. D.; MCCOY, S. W.; PERRON, J. T.; GOREN, L.; CHEN, C. Y. Dynamic reorganization of river basins. Science, v. 343 , n. 6175 , p. $1248765,2014$. 